\title{
The Application of Self-Potential Method on Top of Water Surface for the Detection of Karst Leakage Channel in the Morbid Reservoir
}

\author{
Chen Yixiang ${ }^{1,2}$, Wu Jiangqiang ${ }^{1,2}$, Huang Qibo ${ }^{1,2}$, Gan Fuping ${ }^{1,2}$, Han Kai ${ }^{1,2}$, Yang Chuchang ${ }^{1,2}$, \\ Zheng Zhijie ${ }^{1,2}$ \\ ${ }^{1}$ Institute of Karst Geology, Chinese Academy of Geological Sciences, Guilin, China \\ ${ }^{2}$ Karst Dynamics Laboratory, Ministry of Land and Resources, Guilin, China
}

\section{Email address:}

13807737473@163.com (Chen Yixiang),1191261549@qq.com (Wu Jiangqiang),464383294@qq.com (Huang Qibo), 853941862@qq.com (Gan Fuping),305926876@qq.com (Han Kai), 18925640@qq.com (Yang Chuchang),

522594381@qq.com (Zheng Zhijie)

\section{To cite this article:}

Chen Yixiang, Wu Jiangqiang, H Uang Qibo, Gan Fuping, Han Kai, Yang Chuchang, Zheng Zhijie. The Application of Self-Potential Method on Top of Water Surface for the Detection of Karst Leakage Channel in the Morbid Reservoir. Science Discovery.

Vol. 6, No. 3, 2018, pp. 137-146. doi: 10.11648/j.sd.20180603.11

Received: March 30, 2018; Accepted: June 6, 2018; Published: June 22, 2018

\begin{abstract}
As a result of karst development, water leakage from reservoirs and waste water leakage from mine tailings impoundments often occur in karst region of southwestem China. The geophysical prospecting methods commonly used in the investigation of karst leakage passage are mostly located in the dam, abutment and other land of the reservoir area, which are fail to detect and evaluate the karst collapse at the bottom of the reservoir directly. This will result that the effect of detection and governance are often poor. This paper takes the detection of karst leakage passage beside culvert of the first class hydropower station in Jinjihe reservoir in North Guangxi as an example, studying the principle, field working method and detection effect of detecting karst leakage passage in reservoir by self-potential method on the water. Outcropping formation in the study area mainly consist by the limestone clipped dolomite, dolomitic limestone of Devonian Liujiang formation $\left(\mathrm{D}_{3 \mathrm{~L}}\right)$ and dolomite, limestone, argillaceous limestone of the Devonian Donggangling order $\left(\mathrm{D}_{2 \mathrm{~d}}\right)$. The hidden karst is secondary development. That outlet pipe of the first class hydropower station in the district releases water can cause a strong negative center regional field of self-potential on the water. By dividing the regional field of self-potential on the water using the circumferential mean method and calculating the residual local anomaly separate 6 secondary negative center residual local anomaly of self-potential on the water covered by a strong regional field like an equiaxed or elliptical shape. After check in the reservoir by the diver, the 6 negative center residual local anomaly zone correspond to karst collapse, karst opening or leaking skylight at the bottom of the reservoir. Among them, the negative center residual local anomaly like an equiaxed shape near the survey points $46-48$ of line 16 correspond to the largest karst collapse at the bottom of the reservoir. Through the simple connected experiment of internal and external water and the engineering geological drilling, the effect of geophysical anomaly detection is good. The self-potential method on the water can be used in the investigation of karst geological problems, such as the emergency on the water of the karst sick reservoir, and the rapid delineation of the range of the shallow karst leakage passage.
\end{abstract}

Keywords: Reservoir, Karst Leakage Passage, Self-Potential Method on the Water, Leakage Mechanism, Detection Effect

\section{水上自然电场法及其在病态水库岩溶渗漏通道探测中的应用}

陈贻祥 ${ }^{1,2}$, 邬健强 ${ }^{1,2}$, 黄奇波 ${ }^{1,2}$, 甘伏平 ${ }^{1,2}$, 韩凯 ${ }^{1,2}$, 杨初长 ${ }^{1,2}$, 郑智杰 ${ }^{1,2}$

1 中国地质科学院岩溶地质研究所, 桂林, 中国 
${ }^{2}$ 国土资源部岩溶动力学重点实验室, 桂林, 中国

\title{
邮箱
}

13807737473@163.com (陈贻祥), 1191261549@qq.com(邬健强),464383294@qq.com(黄奇波),853941862@qq.com(甘伏平), 305926876@qq.com（韩凯）, 18925640@qq.com（杨初长),522594381@qq.com（郑智杰）

\begin{abstract}
摘要: 在中国西南岩溶区修建的水库或矿山尾矿库等建筑物, 常因库区岩溶地质条件复杂而出现库水或污水渗漏等问 题, 岩溶渗漏通道勘察中常用的物探方法多布置在库区的大坝、坝肩等库岸陆地一带, 未能对库内的库底岩溶塌陷等 岩溶渗漏通道直接进行探测与评价，致使探测与治理效果往往不佳。本文以中国桂北金鸡河水库一级水电站放水涵管 放水口旁岩溶渗漏通道探测为例, 研究水上自然电场法探测水库岩溶渗漏通道的原理、现场工作方法及探测效果。研 究区出露地层主要由泥盆系榴江组 $\left(\mathrm{D}_{3 \mathrm{~L}}\right)$ 石灰岩夹白云岩、白云质灰岩, 泥盆系东岗岭阶 $\left(\mathrm{D}_{2 \mathrm{~d}}\right)$ 白云岩、石灰岩、 泥质灰岩组成, 隐伏岩溶中等发育。区内一级水电站放水管入水口放水可引起强烈水上自然电位负心区域场, 经采用 两点平均法划分水上自然电位区域场与剩余局部异常, 分离出6个被强烈区域场淹盖了的次级似等轴状或似椭圆状负心 水上自然电位剩余局部异常。经潜水员潜水入库内查看, 这6个负心剩余局部异常区在库底均有岩溶塌陷或岩溶开口或 库底渗漏天窗一一对应, 其中, 第16线46-48号测点附近出现的似等轴状负心剩余局部异常对应的库底岩溶塌陷规模最 大, 塌陷坑直径约 $1.8 \mathrm{~m}$, 塌陷坑深约 $2.5 \mathrm{~m}$, 其余异常区对应的库底渗漏天窗或岩溶开口规模次之。经库内外水的简易 连通实验及工程地质钻探, 物探异常查证效果好。水上自然电场法可用于岩溶病态库区水上应急、快速圈定浅层岩溶 渗漏通道范围等岩溶地质问题调查。
\end{abstract}

关键词: 水库, 岩溶渗漏通道, 水上自然电位, 渗漏机理, 探测效果

\section{1. 引言}

在中国西南岩溶石山区依岩溶洼地或岩溶盲谷修建 的水库或矿山尾矿库等建筑物, 常因库区岩溶地质条件复 杂而出现库水渗漏或污水渗漏等问题, 致使水库蓄水能力 或污染类库区防渗能力未能达到设计要求, 影响工程建筑 物的正常运行, 渗漏严重时水库大坝等建筑物出现严重失 稳、水库干涸、库内污水外泄, 工程建筑物丧失应有的功 能，甚至污染环境、危及下游人民生命与财产安全。病态 水库岩溶渗漏通道的探测与评价, 以及除险加固工程的设 计方案的选择, 物探方法是常用的手段。在水库渗漏通道 勘察中常用的物探方法有常规电法、高密度电阻率法、浅 层地震勘探法、探地雷达、地面自然电场法、跨孔电磁波 CT法和地震波 CT法等方法 $[1]$, 这些探测方法往往布置在 库区的大坝、坝肩等库岸陆地一带, 未能对库区的库底岩 溶塌陷、基岩岩溶开口等渗漏通道直接进行探测与评价, 致使水库渗漏通道除险加固工程针对性不具体, 治理效果 往往不佳, 有待于研发库内岩溶水上探测方法技术。

本文以中国桂北金鸡河水库一级水电站放水涵管库 内放水口旁岩溶渗漏通道探测为例, 研究水上自然电场法 探测水库岩溶渗漏通道的原理、现场工作方法及探测效果, 为岩溶区水库、矿山尾矿库岩溶渗漏通道等相似案例的探 测与评价提供一种可借鉴的地球物理勘探方法。

自然电场法是最早被使用的地球物理勘探方法之一, 于 $1829 \sim 1843$ 年由拉. 维. 傅克斯第一次用在翠绿砷铜矿 脉上, 1913年起, 斯留姆别尔斯在黄铁矿、含铜黄铁矿等 矿床上进行了一系列工作。新中国成立后, 特别是 1970 年代中晚期以来, 该方法在理论和实际应用都得到了长足 发展, 并广泛应用于地质找矿 (黄铁矿、铅锌矿、铜矿等
多金属矿床）、水库与坝体或河堤渗漏探测、地下水勘察 和岩溶深基坑渗漏与涌水勘察等众多领域。王俊业 (2002) 采用自然电场法探测输水管道的渗漏通道的流速 [2], 郑 灿堂 (2005) 应用自然电场法检测土坝渗漏隐患取得较好 的效果 [3], 赫健、孙从炎、陈夷 (2007) 采用自然电场 法和高密度电阻率法探测水库副坝渗漏隐患获得成功 [4], 冷元宝、朱文仲、何剑 (2002) [5], 以及赵瑞、许模 (2011) [6]对中国堤坝隐患及渗漏探测技术现状及展望进行了研 究, 葛双成、江影、颜学军 (2002) 在堤防质量检测中成 功应用自然电场法 [7]。陈贻祥、甘伏平、卢呈杰等 (2012, 2013 ) 在广西来宾市吉利村大型岩溶塌陷区, 基于自然过 滤电场原理, 成功应用自然电场法研究与评价岩溶管道型 岩溶塌陷 [8]。杨磊、周启友（2012）采用自然电位方法 监测非饱和带土壤水分入渗过程 $[9]$, 韩凯、陈玉玲、陈 贻祥等在广西全州县洛潭水库成功采用包括自然电场法 在内的综合物探方法探测主坝岩溶渗漏通道 [10], 程亚平、 蒋灵芝、黎柳月等 (2016) 在广西平果铝厂赤泥堆场采用 了综合物探方法探测隐伏岩溶发育特征 [11]。

在国外, Fritjof fagerlund (2003)在澳大利亚葡萄种植 园, 在抽水井周围布置 10 个电极, 测量自然电场在抽水过 程中的时间变化规律, 通过与试验资料对比、水位降升等 来计算含水层的导水系数 (aquifer's transmissivity) 和平 均渗透率 (average permeability) [12]。A.revil(2006) 利用 自然电场曲线与抽水降升的相关关系来监测地下水位的 变化, 以及包气带的迁移变化, 进而确定包气带的厚度 [13]。J.R. Moore et al.（2011）在美国加利福利亚州内华 
达山脉一冰川湖, 采用自然电场法和高密度电法研究水坝 渗漏获得成功 $[14]$ 。

综上所述, 国外应用地面自然电场法探测岩溶宏观发 育分布特征、松散类地层 (土层) 含水层补给与渗透过程, 以及地下水渗透与运移研究等方面取得了较好的效果, 但 对于岩溶石山洼地库区, 在水上应用自然电场法直接进行 探测与研究库底岩溶塌陷、基岩岩溶开口等渗漏通道, 迄 今尚未见有公开报道。

\section{2. 库区地质背景}

\section{1. 水库概况}

金鸡河水库于1942年6月动工兴建, 由于被日本军国 主义侵略, 水库工程施工于1944年被迫停工。新中国成立 后于1957年至1964年，逐年续建，1970年代、1980年代及 1990年代末又进行多次扩建和除险加固。金鸡河水库主坝 为土石坝, 目前坝高 $20.4 \mathrm{~m}$, 坝全长 $2350 \mathrm{~m}$, 其中主坝长 $180 \mathrm{~m}$, 副坝长 $2170 \mathrm{~m}$, 水库集雨面积 $127 \mathrm{~km}^{2}$, 总库容 2968 万 $\mathrm{m}^{3}$, 为当地及邻区农田灌溉的主要水利枢纽。主坝一带 水工建筑物主要有主坝、溢洪道、放水塔、放水涵管、坝 后一级水电站和放水渠道。坝后一级电站位于放水涵管出 口, 装机2台, 共计装机容量 $1000 \mathrm{kw}$ 。

\section{2. 区域地质概况}

库区位于山前岩溶平原之陇岗地带, 金鸡河自东南向 北西从枕洞屯流入库区, 坝区地形起伏不大, 最大高差约 10 余米, 坝体座落在金鸡河一级或二级阶地的粘土夹砂卵
石层之上。测区岩层为NE倾向, 其倾角一般在 $40 \sim 46^{\circ}$ 之 间变化。库区均为第四系土层覆盖, 其地层由第四系粘土 砂卵石层 $\left(Q_{h}\right)$, 泥盆系榴江组 $\left(D_{3 L}\right)$ 石灰岩夹白云岩、 白云质灰岩, 泥盆系东岗岭阶 $\left(\mathrm{D}_{2 \mathrm{~d}}\right)$ 白云岩、石灰岩、 泥质灰岩组成, 测区西北远处分布有石英砂岩和页岩。

测区NW向构造体系发育, 野外可见NW向断层F1(见 图1)由枕洞村进入库区, 是区内起控制性作用的地质构造。 区内岩溶塌陷发育, 塌坑直径不等, 约1.0-15.0m, 根据库 前峒山村至围塘头村因岩溶塌陷造成的带状或串珠状负 地形或溶潭的分布特征, 推测 $\mathrm{F} 1$ 断层有可能延至库区, 在 峒山村附近通过副坝地区后被第四系粘土卵层覆盖。

区内东岗岭阶泥质灰岩为相对隔水层, 隐伏岩溶主要 发育在其上覆的灰岩、白云岩和白云质灰岩中。根据区内 前人地质资料, 区内浅层岩溶中等发育, 岩溶多沿断层破 碎带及多组断层交汇部位发育, 或者在可溶岩与非可溶岩 界面附近的灰岩和白云岩中发育, 并且溶洞大部分被泥质 充填或半充填。

放水涵管及主坝后一级电站位于泥盆系榴江组 $\left(\mathrm{D}_{3 \mathrm{~L}}\right)$ 石灰岩夹白云岩、白云质灰岩分布区, 浅层岩溶发育, 放 水口附近最深库水深约 10 余米。由于受建库时期的科学技 术水平和经济能力的限制, 尚未能查明库区的浅层岩溶发 育情况, 水利枢纽运行多年后曾在电站厂房后约 $12 \mathrm{~m}$ 、放 水涵管的东侧出现一直径约 $3.5 \mathrm{~m}$ 的岩溶塌陷（图 2 ）, 坝 脚出现较大管涌明流。除放水口外, 库内的放水口外侧一 带出现多处次一级的漏水旋浴, 并且日趋严重。因岩溶地 质问题水工建筑物已存在安全隐患, 急需探明安全隐患区 库内岩溶漏水通道等浅层岩溶发育特征, 以便对水工建筑 进行物除险加固。

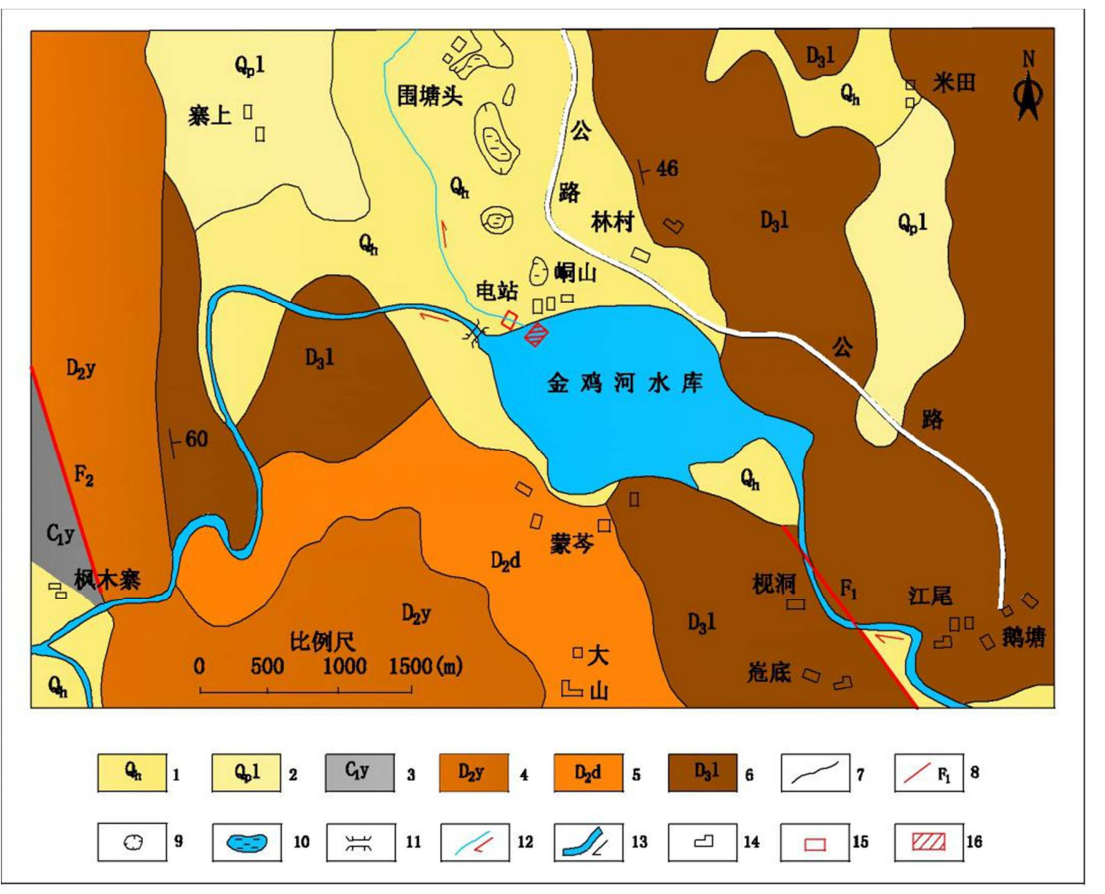

图1 金鸡河水库区域地质简图。

1全新世; 2更新时； 3石炭系岩关组灰岩；4泥盆系郁江组砂岩； 5泥盆系大塘阶灰岩； 6泥盆系榴江组灰岩夹白云岩； 7地层分界线； 8断层及编号； 9溶潭; 10 水库； 11水库主坝； 12渠道；13河流； 14 村庄； 15 水电站；16水上物探工作区 


\section{3. 水上自然电场法工作方法及水上自然电位分 布特征}

\section{1. 水上自然电场法测网布置}

为了探测库内放水管入水口外侧一带的渗漏岩溶开 口或岩溶渗漏通道, 据多种综合物探方法试测结果, 最优 探测方法为水上自然电场法。水上自然电场法测点距和测 线距均为 $2 \mathrm{~m}$, 测线方位角为 $85^{\circ}$ 。测网的施设用森林罗盘 经纬仪定向、测绳量距，布置了第13-18测线共6条水上自
然电场法测线 (图2)。为保证精度水上布点精度, 各测 线均采用粗塑料绳子作测线导向和固定各个不极化电极, 并用塑料泡沫浮托, 以便各个不极化电极置于同一水深度, 使得自然电场数据采集在同一海拔高程, 确保自然电场数 据采集结果的真实性和精度。

此外, 为了研究库内岩溶渗漏通道延伸方向与坝体管 涌及岩溶塌陷的关系, 在主坝外坡、一级电站北面的岩溶 塌陷一带还布置了第11-12测线共2条的地面高密度电测 深法（图2）。

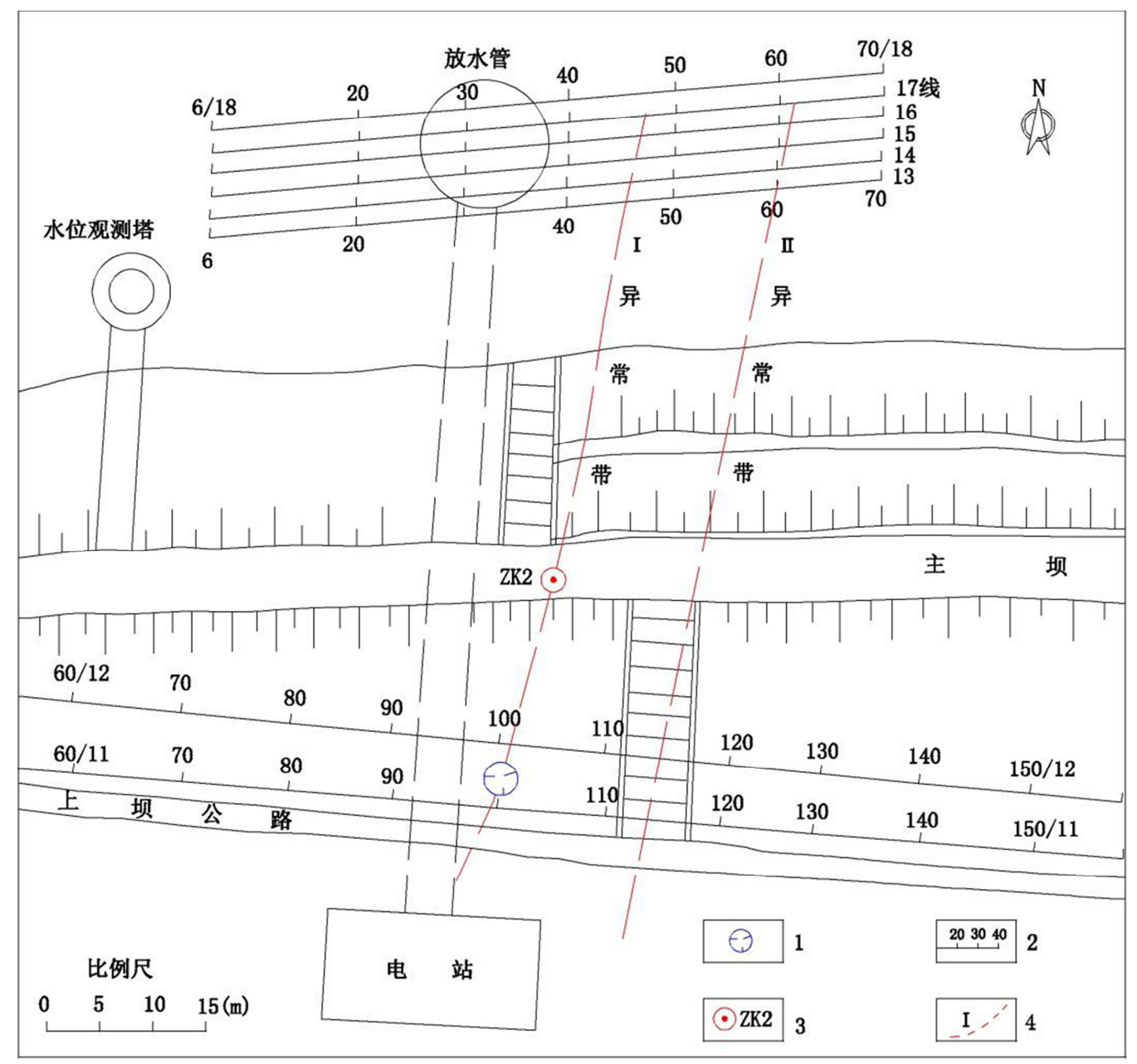

1岩溶塌陷; 2物探测线及编号; 3 地质钻孔及编号; 4推测的岩溶发育异常带及编号

图2 金鸡河水库一级电站物探测线布置图。

\section{2. 水上自然电场法观测系统}

测区水上自然电场及其梯度测量采用列阵式观测系 统, 数据采集时选择接地电阻小于 $2 \mathrm{k} \Omega$ 、极差小于 $2 \mathrm{mV}$ 的 固体不极化电极对进行观测, 固体不极电极统一编号使用, 如固体不极化电极不能满足接地电阻或极差要求时及时 更换。水上自然电场及其梯度数据的采集采用重庆奔腾数 控技术研究所生产的WGMD-3高密度电阻率测量系统完 成（图3），测区各测线自然电场及其梯度测量要求在一 天内快速完成观测, 以减少自然电场随时间变化而影响各
测线观测结果的一致性。水上自然电场观测时的无穷远极 $\mathrm{N}$ 布置在自然电场稳定、库水无风浪、接地条件良好、无 人文电磁干扰源的物探测线中垂线附近, 且要求 $\mathrm{MN}$ 大于 5 倍测线长度。对于观测数据出现突变跳动等情况的测线要 求重测, 以提高信噪比, 保证观测质量。水上自然电场法 数据采集还在测区的东北角设立一个自然电场日变观测 点, 观测区域自然电场日变值, 并对各物探测线实测的自 然电场值进行日变改正。 


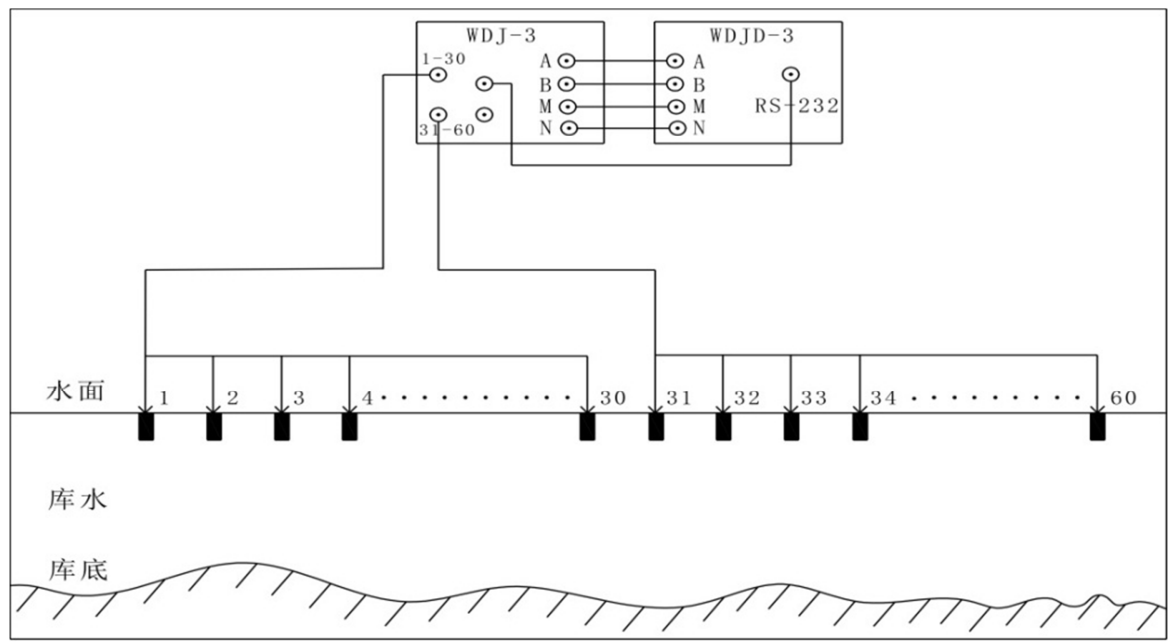

图3 水上自然电场列阵式观测系统示意图。

3.3. 水上自然电位分布特征

\subsection{1. 水上自然电位平面分布特征}

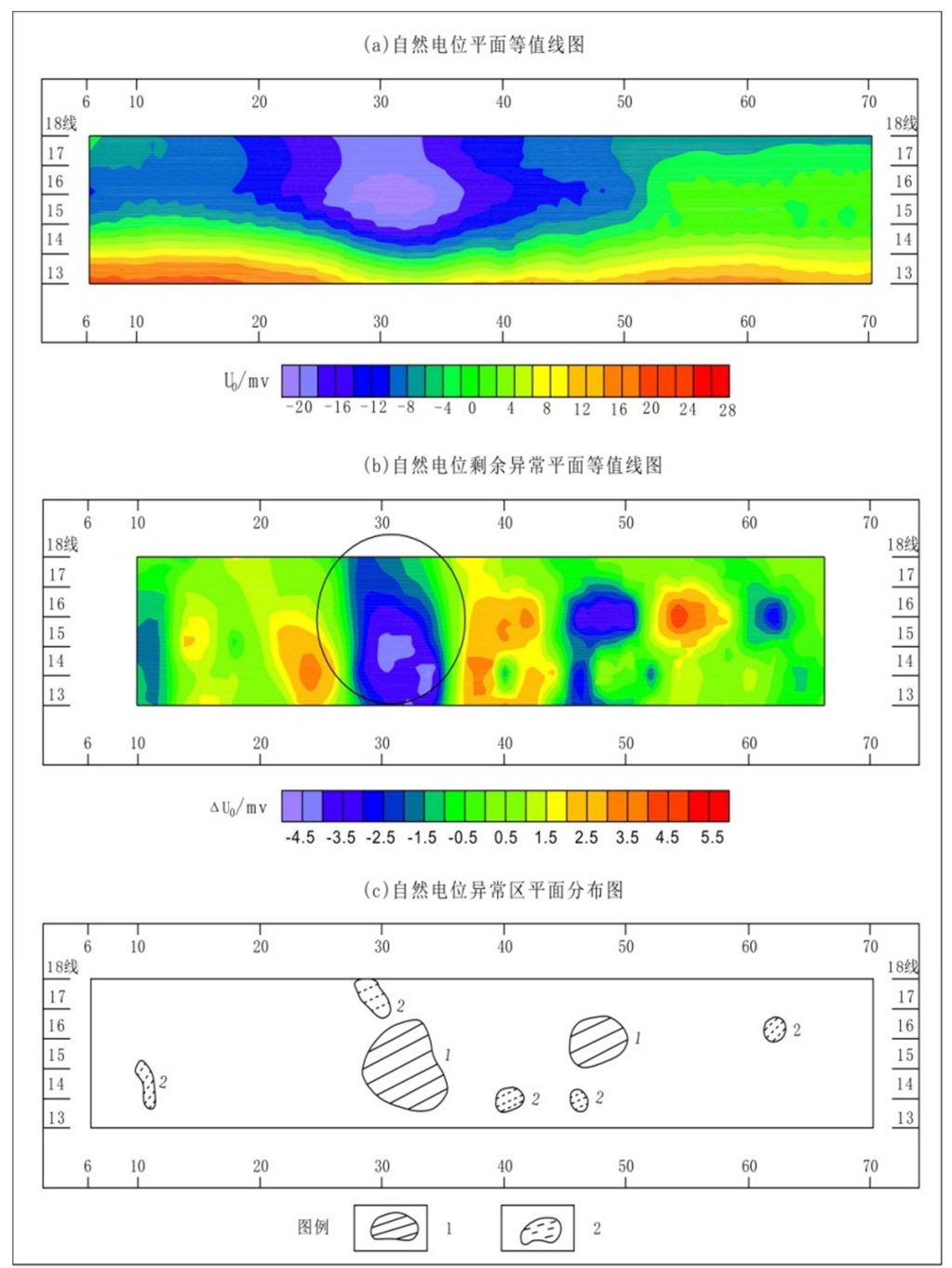

1强渗漏异常区; 2弱渗漏异常区

图4 金鸡河水库一级水电站放水管入水口水上自然电位异常分布平面图。 
测区水上自然电位平面等值线图如图4 (a) 所示, 由 图可见水上自然电位在以 16 线 30 号测点为中心出现了相 对幅值约为-23.5mv似椭圆状负心异常区, 此似椭圆状负 心异常区与放水管入水口位置吻合, 为放水管入水口放水 引起的强大一级自然电位异常, 此异常在研究水库浅层微 小岩溶渗漏通道时可视为区域场。此外, 在似椭圆状负心 异常区的两侧还叠加了由地质结构变化等因素引起的次 一级负值异常, 使得测区水上自然电位平面等值线呈近东 西向拉长状和复杂化, 也就是说, 放水管入水口放水引起 的强大一级自然电位区域异常淹盖了由其它因素变化引 起的次一级负值异常, 次一级负值异常特征难以识别。

\subsection{2.水上自然电位区域场与剩余异常的划分方法}

测区水上自然电位区域场划分后的剩余自然电位异 常, 即为浅层微小岩溶渗漏通道、地质结构变化等因素 产生的自然电位异常, 该自然电位异常与水库补给岩溶 地下水的关系密切, 它较为直观地指示了水库库底岩溶 渗漏通道平面位置和渗漏强度。水上自然电位区域场与 剩余异常的划分采用圆周平均法, 即以半径为 $\mathrm{R}$ 的圆周上 各测点的自然电位原始观测值之平均值作为圆心上测点 的自然电位区域场来划分自然电位区域场与剩余异常, 当半径 $\mathrm{R}=$ 测点距 $=$ 测线距时, 圆周平均法计算公式可简 化为:

$$
\Delta \mathrm{U}_{i, j}=\mathrm{U}_{i, j}-\left(U_{i-1, j}+U_{i, j-1}+U_{i, j+1}+U_{i+1, j}\right) / 4
$$

式中, $\Delta \mathrm{U}_{i, j}$ —第 $\mathrm{i}$ 测线第 $\mathrm{j}$ 测点的剩余自然电位值; $\mathrm{U}_{i, j}$ —第 $\mathrm{i}$ 测线第 $\mathrm{j}$ 测点的自然电位观测值;

$U_{i-1, j}$ —第 $\mathrm{i}-1$ 测线第 $\mathrm{j}$ 测点的自然电位观测值; $U_{i, j-1}$ 第 $\mathrm{i}$ 测线第 $\mathrm{j}-1$ 测点的自然电位观测值;

$U_{i, j+1}$ —第 $\mathrm{i}$ 测线第 $\mathrm{j}+1$ 测点的自然电位观测值;

$U_{i+1, j}$ —第 $\mathrm{i}+1$ 测线第 $\mathrm{j}$ 测点的自然电位观测值;

$i=1 、 2 、 3 \ldots \ldots ; j=1 、 2 、 3 \ldots \ldots$ 。

当测线数较少时, 仅能单一测线进行区域场与剩余异 常的划分, 此时圆周平均法计算公式 (1) 进一步简化为 两点平均法计算公式:

$$
\Delta \mathrm{U}_{i, j}=\mathrm{U}_{i, j}-\left(U_{i, j-1}+U_{i, j+1}\right) / 2
$$

\subsection{3. 水上自然电位剩余异常平面分布特征}

测区水上自然电位区域场与剩余异常的划分采用两 点平均法（图5），剩余异常平面等值线图如图4（b）所 示, 由图可见水上自然电位剩余异常仍在以 16 线 30 号测点 附近为中心出现了相对幅值约为 $-4.75 \mathrm{mv}$ 似陏圆状负心异 常区, 此似陏圆状负心异常区分布范围较大, 并与放水管 入水口位置吻合。此外, 在似粗圆状负心异常区的两侧还 出现了 6 个微小次一级负心局部异常, 其中, 以 16 线 $46-48$ 号测点附近出现的次一级负心异常最为强烈, 其幅值约为 $-4.68 \mathrm{mv}$, 其余 5 个水上自然电位剩余局部负心异常强度则 较弱, 其幅值约为 $-1.37-3.78 \mathrm{mv}$ 之间。
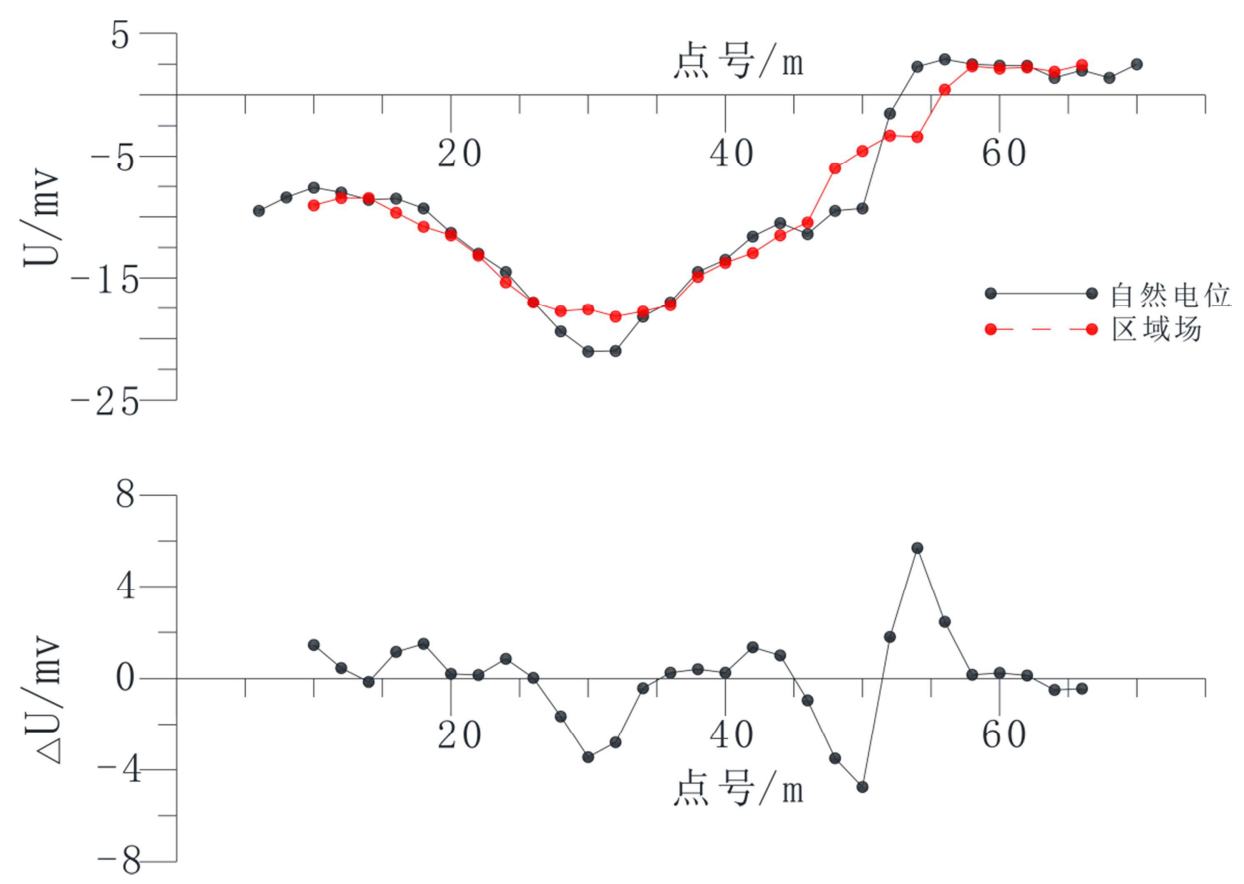

图5 金鸡河水库第16测线水上自然电位区域场与剩余异常剖面曲线。

从负心局部异常的形态划分, 测区水上自然电位局 部剩余异常形态多呈似等轴状或似椭圆状负心异常; 从 负心异常强度的划分, 测区水上自然电位剩余局部异常 可划分为强渗漏异常区和弱渗漏异常区。水上自然电位 剩余局部异常与陆地第11及12测线视电阻率联合法“同步
低”异常（图6）综合分析, 测区综合物探异常带沿近南北 方向由库内穿越主坝后延伸至库外呈线性分布, 可划分 为 I 和 II 两条线性异常带 (图2)。 


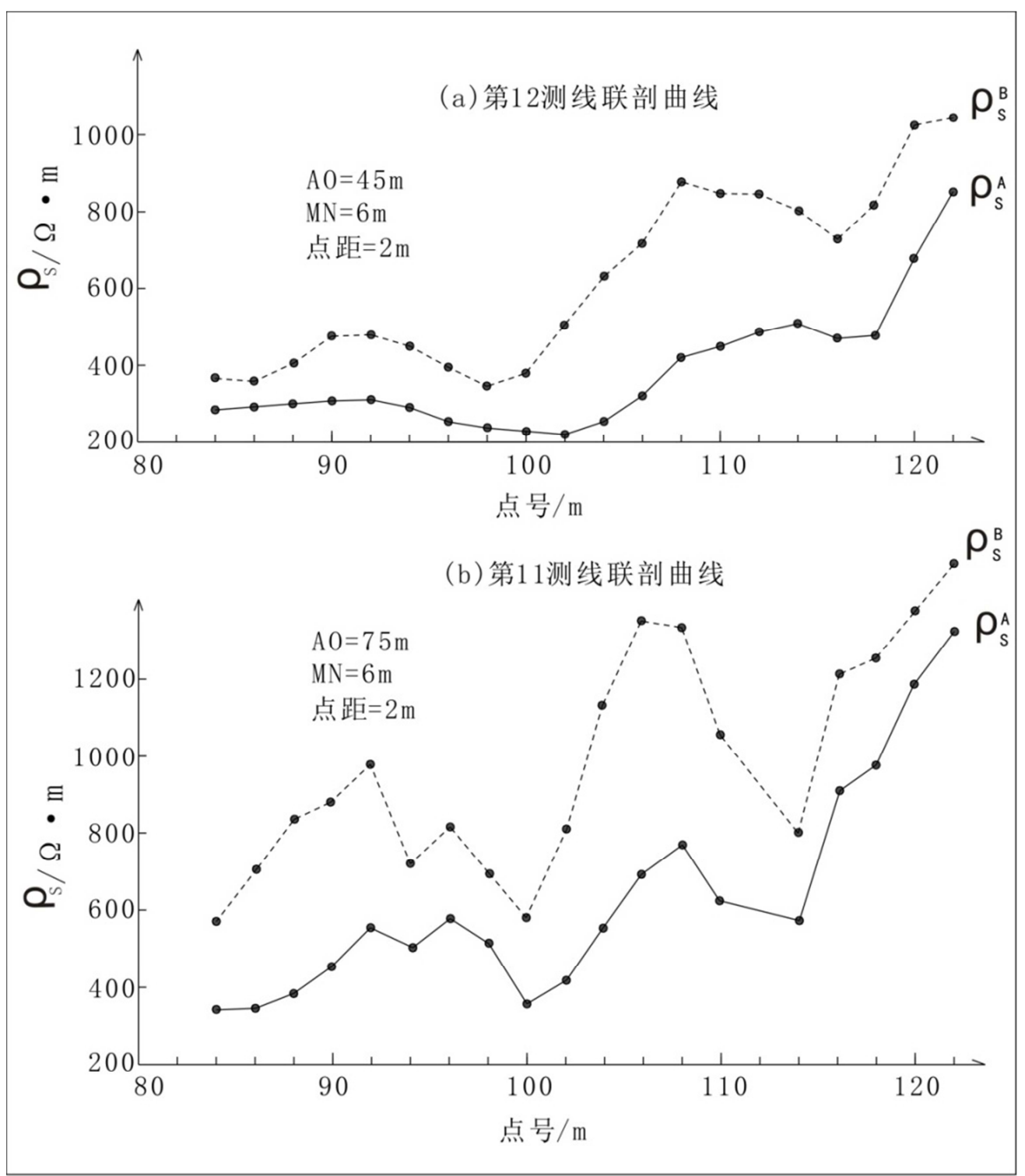

图6 金鸡河水库第11、12测线视电阻率联合剖面曲线。

\section{4. 讨论}

\section{1. 库区浅层岩溶渗漏自然电场形成机理}

库底土层在库水长期浸泡软化、库水渗透压力作用和 深层岩溶水通过岩溶裂隙网络或溶孔等岩溶通道对上覆 土体的潜蚀作用下, 库底土层易发生库底岩溶塌陷, 在基 岩面上形成岩溶开口, 地表水 (库水) 可通过岩溶开口和 岩溶裂隙网络或溶孔直接坚向补给地下水, 形成自上而下 的相对优势渗漏流。此自上而下的相对优势渗漏流将带走 大量游离在库水中的正电荷 (阳离子) , 这样在渗漏流的 上游 (库水中) 留下剩余负电荷(阴离子)、在渗漏流的下
游（地下岩溶管道等）形成正电荷(阳离子)的堆积, 进而 破坏了正、负电荷的平衡, 引起离子导电库水的自然极化, 形成自上而下的渗漏流电位差, 该渗漏流电位通过外电路 (地下岩土层和库水等) 不断放电, 形成范围相对较大的 负心自然电场（图7）。当土层和岩石岩溶蚀裂隙网络或 溶孔等岩溶通道同时存在时, 库底岩溶渗漏通道产生的自 然电场是土层、岩溶裂隙网络或溶洞中地下水渗流的综合 反映或贡献。因此, 通过在水库水面研究浅层岩溶自然电 场的时空分布特征, 便可采用自然电场法来探测水库库底 岩溶地下渗漏通道。 


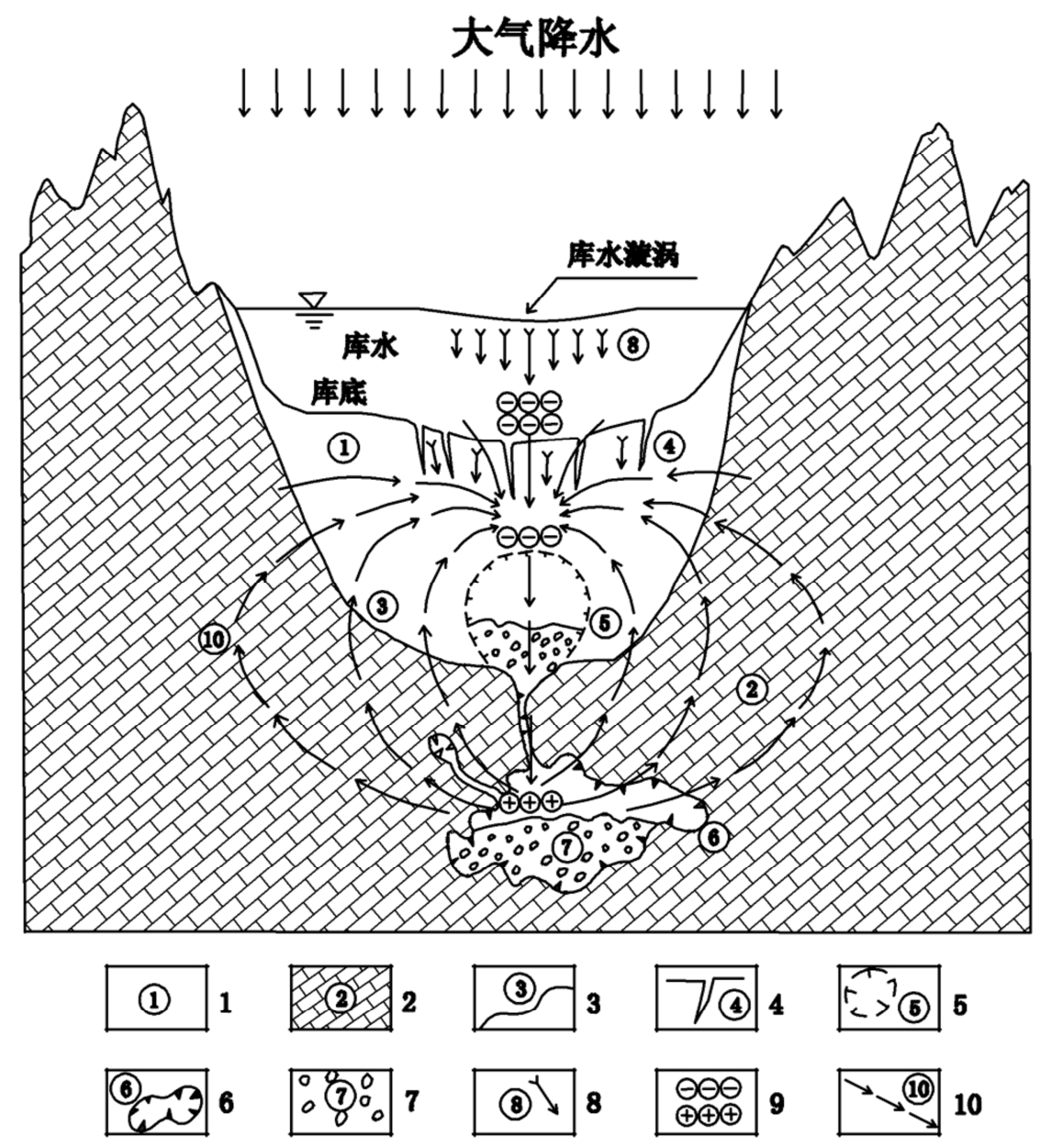

1土层； 2石灰岩; 3 基岩面; 4地裂缝; 5 土洞； 6溶洞； 7洞内沉积物； 8 库水下渗流流向；9库水剩余正、负离子； 10 水上自然电场电力线

图7 岩溶洼地水库库水渗漏流自然电场分布示意图。

\section{2. 水上自然电位剩余异常的地质解释及其效果分析}

测区水上自然电位似等轴状或似椭圆状负心剩余局 部异常是地表水 (库水) 通过库底岩溶开口或岩石岩溶蚀 裂隙网络或岩溶塌陷直接坚向补给岩溶地下水, 形成自上 而下的自然极化电场所致。水上自然电位似等轴状或似椭 圆状负心剩余局部异常形态恰好指示了库底岩溶塌陷、土 岩界面岩溶开口或库底渗漏天窗等岩溶地质现象的平面 位置（图4（c）），位于16线46-48号测点的水上自然电 位似等轴状区与次级库水旋浴水花分布区较吻合。测区综 合物探方法发现的 I 和 II 线性异常带与浅层岩溶发育有 关，其中 I 线性异常带北起16线46-48号测点的水上自然 电位似等轴状负心剩余局部异常区, 往南向库外延伸至主 坝外坡一级电站北面的岩溶塌陷一带, 最后延伸至电站厂 房内, 并与坝脚出现的较大管涌明流位置相吻合 (图2)。

根据物探异常, 在主坝顶布置的工程地质钻孔ZK2验 证了 I 线性异常带的存在, ZK2 孔验证结果: 0-18.3m孔深 段为填筑黏土， $18.3-24.5 \mathrm{~m}$ 孔深段为原状黏土混卵石， 24.5-33.55m孔深段为泥盆系东岗岭阶 $\left(\mathrm{D}_{2 \mathrm{~d}}\right)$ 深灰色石灰 岩、岩芯溶蚀裂隙发育、岩芯破碎其采取率约 $10 \%$ 、钻探 施工用水全漏并在主坝外坡一级电站北面的岩溶塌陷坑 溢出，33.55-34.68m孔深段为半充填溶洞，34.68-39.68m
孔深段为泥盆系东岗岭阶 $\left(D_{2 d}\right)$ 深灰色溶蚀裂隙石灰岩、 岩芯较破碎其采取率约 $75 \%$ 。基本查明了探测区位岩溶渗 漏通道等浅层岩溶带的发育情况, 为水工建筑物的除险加 固工程的方案设计与施工提供了地质依据。

库内水上自然电位似等轴状或似椭圆状负心剩余局 部异常的验证由潜水员潜水入库内查看完成, 查看结果表 明, 水上自然电位出现的似等轴状或似椭圆状负心剩余局 部异常区在库底均有岩溶塌陷或岩溶开口或库底渗漏天 窗一一对应, 其中, 16线46-48号测点附近出现的似等轴 状负心剩余局部异常对应的库底岩溶塌陷规模最大, 塌陷 坑直径约 $1.8 \mathrm{~m}$, 塌陷坑深约 $2.5 \mathrm{~m}$, 潜水员在此坑旁有库水 向下潜流感, 当在此坑投入较大剂量食品红后约 8 分钟时, 在主坝外坡一级电站北面的岩溶塌陷坑管涌渗流中溢出 红水, 说明水库内外两坑之间水力连通性良好。其余异常 区对应的库底渗漏天窗或岩溶开口规模次之, 直径约 $0.5-1.0 \mathrm{~m}$ 。

水工建筑物除险加固工程施工时, 库底岩溶塌陷或岩 溶开口或库底渗漏天窗采用了片石回填铺盖措施, 主坝坝 基岩溶治理采用了钻孔帷幕灌浆法加固, 主坝坝体采用了 人工挖孔连续墙防渗除险加固措施, 水工建筑物险情得以 排除。 


\section{3. 水上自然电位法干扰因素分析}

由于库底岩溶塌陷、土岩界面岩溶开口或库底渗漏天 窗等岩溶渗漏通道产生的自然电位分布范围较小、梯度变 化大、异常幅值较微弱, 因此, 水上自然电场法测点的平 面点位误差、不极化电极的埋置入水深度误差及埋置稳定 性的优劣将直接影响水上自然电位的观测精度。岩溶病态 水库水上自然电场法也存在一些干扰因素, 不同的探测目 的干扰因素各异, 有意义异常与干扰异常的区分由探测目 的而定。对于岩溶病态水库浅层岩溶渗漏通道探测而言, 放水管入水口放水引起的强大自然电位, 在研究水库浅层 局部岩溶渗漏通道时可视为区域场。此外，岩溶区隐伏金 属矿床和炭质灰岩等岩层物性变化产生的水上自然电场 即为干扰因素。在水工建筑物中的钢筋混凝土、电器机壳 接地游散电流、高压输电网、通信光缆、地下金属管道(线) 等人文电磁场干扰区,水上自然电位法观测精度达不到质 量要求,可采用避让法、排除法、在线监测法加以消除或 提高信噪比。

\section{5. 结论}

岩溶病态水库库底土层在库水长期浸泡软化、库水渗 透压力作用和深层岩溶水通过岩溶裂隙网络等岩溶通道 对上覆土体的潜蚀作用下, 库底土层易发生库底岩溶塌陷, 在基岩面上形成岩溶开口, 地表水 (库水) 将通过基岩面 岩溶开口和岩溶裂隙网络等通道直接坚向补给深层岩溶 地下水, 形成自上而下的相对优势渗漏流, 进而形成自然 极化电场。此自然极化电场为采用水上自然电场法探测岩 溶病态水库库底岩溶塌陷或岩溶开口或库底渗漏天窗等 岩溶渗漏通道成为可能。由于充分利用了地表水 (库水) 和岩溶地下水渗漏流的水动力条件, 水上自然电场法以其 特有的库水动态自然极化机理、观测系统及高精度分辨率, 在库内水上寻找岩溶病态水库、矿山尾矿库等建筑物浅层 岩溶渗漏通道等方面具有明显的探测优势, 该方法要比其 它物探方法更有利于在库内水上快速圈定浅层岩溶发育 范围, 可用于岩溶病态库区应急岩溶地质问题调查。

金鸡河水库一级水电站放水管入水口放水可引起强 大一级水上自然电位负心异常, 此异常在研究水库库底浅 层微小岩溶渗漏通道时可视为区域场, 在此强大一级水上 自然电位区域场上叠加了 6 个相对微小次一级水上自然电 位负心局部异常, 其中, 以16线46-48号测点附近出现的 次一级负心异常最为强烈, 其幅值约为 $-4.68 \mathrm{mv}$, 其余 5 个 水上自然电位剩余局部负心异常强度则较弱, 其幅值约为 -1.37- $3.78 \mathrm{mv}$ 之间。这类局部异常多呈似等轴状或似椭 圆状, 它们直观地指示了库底岩溶塌陷、岩溶开口或库底 渗漏天窗等岩溶地质现象的平面位置, 经潜水员潜水入库 内查证, 似等轴状或似椭圆状负心剩余局部异常区在库底 均有岩溶塌陷或岩溶开口或库底渗漏天窗一一对应, 位于 16线46-48号测点附近出现的似等轴状负心剩余局部异常 对应的库底岩溶塌陷规模最大, 塌陷坑直径约 $1.8 \mathrm{~m}$, 塌陷 坑深约 $2.5 \mathrm{~m}$, 潜水员在此坑旁有库水向下潜流感, 当在此 坑投入较大剂量食品红后约8分钟时, 在主坝外坡一级电 站北面的岩溶塌陷坑管涌渗流中溢出红水, 说明水库内外
两坑之间水力连通性良好。其余异常区对应的库底渗漏天 窗或岩溶开口规模次之, 直径约 $0.5-1.0 \mathrm{~m}$ 。这些库内岩溶 塌陷坑或岩溶开口是探测区内主要的渗漏通道, 水上自然 电场法探测查证效果好。

水上自然电场法的点位误差、不极化电极埋置稳定性、 水上自然电位区域场和剩余异常的识别与划分方法、人文 电磁场及岩层物性变化等干扰因素的优劣将直接影响水 上自然电位的观测精度和分辨率以及探测效果。目前, 水 上自然电场法可在库内水上快速圈定浅层岩溶发育范围 和岩溶病态库区应急抢险岩溶地质问题调查中发挥积极 作用, 但适合于水上自然电场法电位剩余局部异常的三维 快速反演方法将有待于未来进一步研究。

\section{致谢}

本文得到了国家自然科学基金项目（41572232）、中 国地质调查局项目（DD20160301）、中国地质科学院基 本科研项目（YYWF201640）、中国地质科学院基本科研 项目 (YYWF201643) 的资助。作者非常感谢编辑部付出 的大量辛勤劳动, 并虚心接受匿名评审专家为本文的完善 提出的大量宝贵意见和建议, 作者向匿名评审专家致以谢 意!

\section{参考文献}

[1] 石昆法, 戚洪涁, 王斌. 地层含水性研究的地球物理方法 [J]. 地球物理学进展, 2002, 17 (4):636-643。

[2] 王俊业. 应用自然电场法研究地下水流场 $[J]$. 物探与化探, 2002, 26 (2) : 140-142。

[3] 郑灿堂. 应用自然电场法检测土坝渗漏隐患的技术 $[\mathrm{J}]$. 地 球物理学进展, 2005, 20（3）:854-858。

［4］赫健, 孙从炎, 陈夷. 自然电场法和高密度电阻率法在天子 岗水库副坝渗漏隐患探测中的应用 $[\mathrm{J}]$. 浙江水利科技, 2007, 153 (5) :45-47。

[5] 冷元宝, 朱文仲, 何剑, 等. 我国堤坝隐患及渗漏探测技术现 状及展望 $[J]$. 水利水电科技进展, 2002, $22(2)$ : 59-62。

[6] 赵瑞, 许模. 水库岩溶渗漏及防渗研究综述 [J]. 地下水, 2011, 33 (2):20-22。

[7] 葛双成, 江影, 颜学军. 综合物探方法在堤防质量检测中的 应用 $[J]$. 地球物理学进展, 2006, 21 (1) :263-272。

[8] 陈贻祥, 甘伏平, 卢呈杰, 韦吉益. 岩溶塌陷自然电场及其应 用 [J]. 中国岩溶，2013，32(4)：480-486。

［9］杨磊, 周启友. 基于自然电位方法的非饱和带水分分布和运 移情况探测 [J]. 工程勘察，2012，（12）：84-89。

[10] 韩凯, 陈玉玲, 陈贻祥, 等. 岩溶病害水库的渗漏通道探测 方法一一以广西全州县洛潭水库为例 $[\mathrm{J}]$. 水力发电学报, 2015, 34 (11) : 116-125。 
[11] 程亚平, 蒋灵芝, 黎柳月, 等. 综合物探技术探测平果铝厂 赤泥堆场岩溶发育特征 [J]. 中国岩溶, 2016, 35(6)： 688-698。

[12] Fritjof Fagerlund, Graham Heinson. Detecting subsurface groundwater flow in fractured rock using self-potential(sp) methods [J]. Environmental Geology, 2003, 43: 782-794.

[13] A. Revil, K. Titov, C. Doussan, and V. Lapenna. Applications of the self-potential method to hydrological problems [M]. Applied Hydrogeophysics, 255-292.

[14] Jeffrey R. Moore, Alexandre Boleve, Johnny W. Sanders, Steven D. Glaser. Self-potential investigation of moraine dam seepage [J]. Journal of Applied Geophysics, 74 (2011): 277 286.

\section{作者简介}

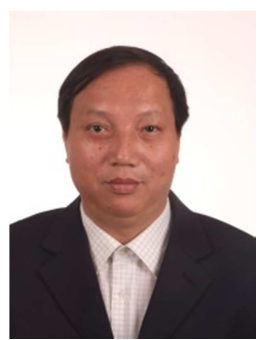

陈贻祥（1959-），男，教授级高级工 程师。主要从事岩溶地球物理勘探方法 的应用研究工作, 主持完成或正在进行 的国家自然科学基金项目、中国地质调 查局项目及国家大型工程建设项目岩 溶探测多项, 以第一作者在国内外公开 发表科技论文 20 余篇, 公开出版合 著 科技著作4部。 